\title{
Vulvar Merkel Cell Carcinoma: A Rare Entity
}

\author{
${ }^{1}$ Monica Soni, ${ }^{2}$ Sudesh Aggarwal, ${ }^{3}$ Prasoon Soni, ${ }^{4}$ Puja Gupta, ${ }^{4}$ Shaifali Dadhich, ${ }^{5}$ Sharadlata Saini \\ ${ }^{1}$ Assistant Professor, Department of Obstetrics and Gynecology, SP Medical College and PBM Groups of Hospitals, Bikaner, Rajasthan, India \\ ${ }^{2}$ Associate Professor and Head, Department of Obstetrics and Gynecology, SP Medical College and PBM Groups of Hospitals \\ Bikaner, Rajasthan, India \\ ${ }^{3}$ Senior Resident, Department of Dermatology, SP Medical College and PBM Groups of Hospitals, Bikaner, Rajasthan, India \\ ${ }^{4}$ Senior Resident, Department of Obstetrics and Gynecology, SP Medical College and PBM Groups of Hospitals, Bikaner, Rajasthan, India \\ ${ }^{5}$ Resident, Department of Obstetrics and Gynecology, SP Medical College and PBM Groups of Hospitals, Bikaner, Rajasthan, India
}

Correspondence: Monica Soni, C/o Dr KP Soni, Assistant Professor, Department of Obstetrics and Gynecology, IV E 477-78 JN Vyas Colony, Bikaner-334003, Rajasthan, India, Phone: 9982350350, 0151-2234129, e-mail: drmonikasoni3008@gmail.com

\section{ABSTRACT}

Merkel cell carcinoma is a primary small cell carcinoma of the skin that resembles oat cell carcinomas of the lung. This tumor has a predilection for head and neck region but may rarely occur as isolated vulvar tumor. It has aggressive malignant behavior and should not be missed while evaluating vulvar masses. We report a case of 45 -year-old Mrs I, who presented with recurrent vulvar swelling and was diagnosed as stage III Merkel cell carcinoma of the vulva.

Synonyms: Primary neuroendocrine carcinoma, Trabecular carcinoma, Primary small cell carcinoma, Cutaneous apudoma.

Keywords: Vulvar carcinoma, Merkel cell carcinoma.

\section{CASE REPORT}

45-year-old Mrs I was admitted in our department with chief complaint of recurrent swelling in perineal region for 2 years. Initially, it developed as a small, firm nodular growth on the right labia majora. It increased in size over 2 to 3 months but was painless. It was diagnosed as vulval cyst. Bartholin cyst was excised by a local doctor. Histopathology was not done. The growth recurred over 6 to 7 months and this time it was larger than earlier but painless. Excision was done again by a private practitioner. Histopathology report showed Merkel cell carcinoma, and the patient was referred to higher center but she did not comply. Over a period of 8 to 9 months, the growth recurred again and gained a large size.

On admission, general condition of patient was stable. Pulse was 84 per minute and blood pressure was 130/80 mm Hg. Patient was afebrile. Her height was 5 feet 2 inches and weight was $45 \mathrm{~kg}$. Mild pallor was present. Liver and spleen were not palpable. There was no abdominal distension, guarding or, rigidity. Pedal edema was not there.

On local examination, there was a multilobulated, irregular growth (Fig. 1) of about 8 to $10 \mathrm{~cm}$ involving labia majora and minor a (more of right side). Inguinal lymph nodes were enlarged. Other lymph nodes were not enlarged. Distant metastasis was not there. Per speculum, per vagina and per rectal examinations were normal. Further work-up was done and the patient was staged as stage III Merkel cell carcinoma of vulva (Fig. 2). The patient was given three cycles of chemotherapy (cisplatin, cyclophosphamide, methotrexate) but patient did not return for follow-up after 12 March 2010.

\section{DISCUSSION}

Vulvar cancer represents 3 to $5 \%$ of malignancies of the female genital tract. ${ }^{3}$ Approximately 90 to $92 \%$ of all invasive vulvar cancers are of the squamous cell type. ${ }^{3}$ Merkel cell carcinoma is a primary small cell carcinoma of the skin that resembles oat cell carcinoma of the lung. ${ }^{3}$ This tumor has a predilection for the head and neck region followed by the extremities and the buttocks, ${ }^{2}$ but may rarely occur as isolated vulvar tumor. ${ }^{3}$

Merkel cell carcinoma is a relatively recently described entity, although the Merkel cell was described more than 100 years ago $^{1}$ (in 1875, by Friedrich S Merkel). In 1980, the name Merkel cell carcinoma was first used. ${ }^{1}$

This tumor is a malignant proliferation of highly anaplastic cells which share structural and immunohistochemical features with various neuroectodermally derived cells, including cutaneous Merkel cells. ${ }^{2}$

Clinical features are solitary, rapidly growing nodule, ${ }^{2}$ which are firm red, purple or skin colored. It is locally aggressive with local discontinuous and distant lymphatic spread. ${ }^{1}$ Histologically, small round blue cells are present in various growth patterns, out of which, a sheet-like growth is the most common. ${ }^{2}$ Characteristically, the edge of the tumor shows a trabecular infiltrating pattern. ${ }^{2}$ High mitotic rate, frequent single cell necrosis and often zonal necrosis are observed.

A "perinuclear dot", pattern of cytokeratin-20 on immunohistochemical staining is essentially pathognomonic for Merkel cell carcinoma. ${ }^{1} \mathrm{~S}-100$ is positive in most melanomas and negative in Merkel cell carcinoma. ${ }^{1}$ 


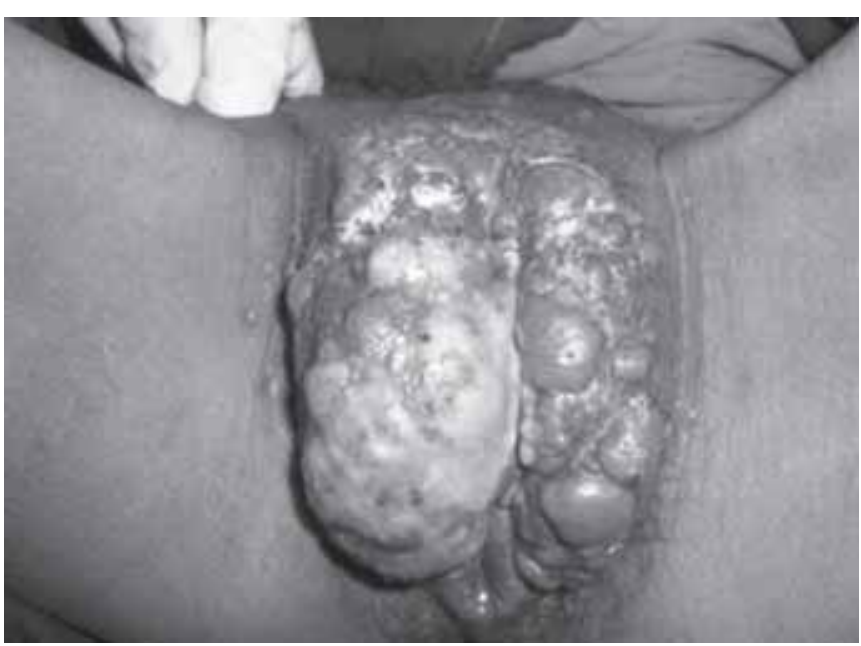

Fig. 1: Gross appearance

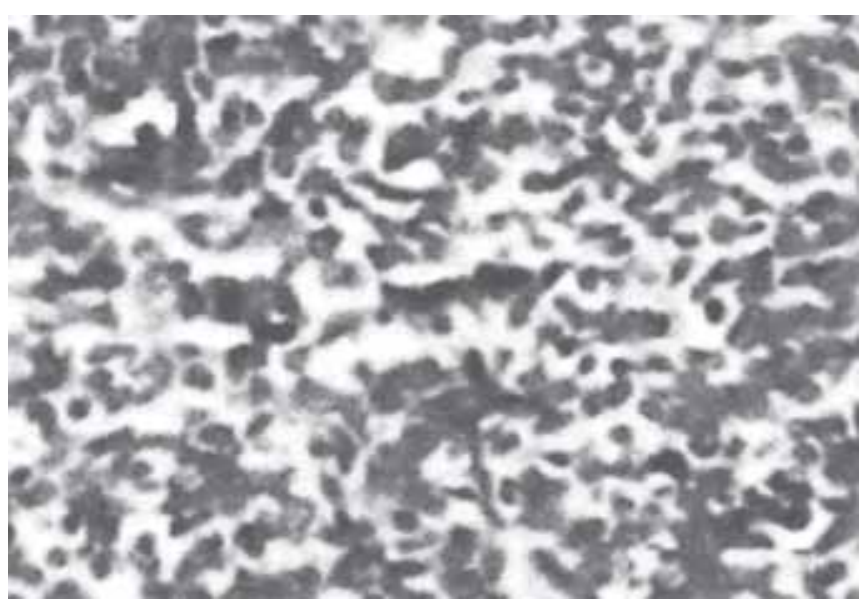

Fig. 2: Histological picture
According to American Joint Committee on Cancer, there are four clinical stages for MCC based on features, at time of presentation. ${ }^{1}$ Localized disease is either stage I (primary lesion $\leq 2 \mathrm{~cm}$ ) or stage II (primary lesion $>2 \mathrm{~cm}$ ). ${ }^{1}$ Nodal spread of MCC is stage III, whereas patients presenting with metastatic disease beyond the local node bed have stage IV disease. ${ }^{1}$

MCC shows aggressive malignant behavior. ${ }^{1}$ Treatment is challenging and controversial. Best outcome is obtained with multidisciplinary approach, including surgery, chemotherapy (cisplatin-based), immunotherapy and radiation therapy. ${ }^{1-3}$ In this case, recurrence can probably be explained by positive surgical margins and lack of chemo/radiotherapy.

Sentinel lymph node biopsy is also a sensitive test for detecting MCC spread to the lymph nodes. ${ }^{1}$

Survival is highly dependent on the stage at presentation. Patients with truly local only disease have a grater than $90 \%$ of chance of survival, which decreases to approximately $60 \%$ with nodal involvement and below $10 \%$ among those presenting with metastatic disease.

\section{REFERENCES}

1. Nghiem P, Jaimes N. Merkel cell carcinoma. Wolff K, Goldsmith LA, Katz SI, Gilchrest BA, Paller AS, Leffel DJ (Eds). Fitzpatrick's Dermatology in General Medicine, Mc Graw Hill Publications 2008;7(1):1087-94.

2. Argenyi ZB. Neural and neuroendocrine neoplasms. Bolognia JL, Jorizzo JL, Rapini RP (Eds). Dermatology. Sec XIII-XVIII, Gurgaon, Elsevier 2008;2(3):1805-07.

3. Holschneider CH, Berek JS. Vulvar Cancer. Berek JS, Berek and Novak's Gynaecology (14th ed). Philadelphia, Lippincott Williams and Wilkins 2007:1575. 